\title{
A ASSISTÊNCIA ESTUDANTIL E A REDUÇÃO DAS DESIGUALDADES SOCIAIS NO CONTEXTO DE FRAGILIZAÇÃOO DAS POLITICAS SOCIAIS
}

\author{
ERNNY Cô̂LHO RÊGO \\ Instituto Federal de Educação do Ceará (IFCE), Fortaleza, Ceará, Brasil \\ MarinINA GrusKa BeneVIDES \\ Universidade Federal do Ceará (UFCE), Fortaleza, Ceará, Brasil
}

\begin{abstract}
Resumo: Este artigo reflete sobre a política de assistência estudantil no contexto neoliberal de fragilização das políticas sociais. Propomos o exercício reflexivo sobre as contraditoriedades da política social que pretende democratizar a permanência ao ensino superior, mas é equacionada pelo modelo neoliberal de Estado mínimo. A metodologia empregou a pesquisa documental às principais legislações nacionais, além da pesquisa bibliográfica. A assistência estudantil configura-se potencialmente estratégica para a democratização do acesso e da permanência no ensino superior público, contudo os contingenciamentos operados pela lógica neoliberal às políticas sociais nos países de economia periférica delineiam ações que não coadunam com o compromisso de incluir socialmente pela educação, operando a formulação de programas focalizados e fragmentados que apresentam dificuldades na garantia do direito.
\end{abstract}

Palavras-chave: Política Social. Assistência Estudantil. Neoliberalismo. Educação.

\section{INTRODUÇÃO}

As políticas públicas sociais de acesso e permanência da educação superior são matéria relativamente recente na agenda de políticas públicas no Brasil. Embora haja estudos que apontem a existência de restaurantes, casas de apoio e demais equipamentos desde a fundação das primeiras universidades, é somente com a Constituição Federal em 1988, e demais legislações - Lei de Diretrizes e Bases em 1996, e o Programa Nacional de Assistência Estudantil - PNAES, instituído pelo Ministério da Educação, por meio da Portaria Normativa no 39/2007, sendo esta ratificada em 2010 que a intervenção estatal em ações de promoção do acesso e permanência ao ensino superior passa a acontecer de forma sistemática nas Instituições de Ensino Superior IES. 
A expansão do ensino superior, as políticas afirmativas, os programas de assistência estudantil e a destinação do orçamento público às demandas sociais ocorrem não sem o tensionamento que é próprio do cenário político-econômico no qual nos situamos. As políticas de assistência estudantil sofrem os rebatimentos de um cenário neoliberal adverso e contraditório, onde as políticas sociais se deparam com a conjuntura de focalização e privatização.

Assim, buscamos com este trabalho debater como a política de assistência estudantil tem sido delineada no cenário de fragilização das respostas estatais pela lógica neoliberal. Propomos o exercício reflexivo sobre as contradições da política social que pretende democratizar a permanência ao ensino superior, mas é equacionada pelo modelo neoliberal de Estado mínimo.

A abordagem metodológica envolveu a pesquisa documental e bibliográfica. Para tanto o trabalho será desenvolvido a partir das categorias de análises que lhe dão direcionamento, quais sejam: "1. Política Pública Social: um elemento contraditório"; momento em que empreendemos o debate sobre a concepção de política social no contexto neoliberal, "2. Da educação enquanto direito: as políticas públicas para a educação superior no Brasil"; e "3. Assistência Estudantil: uma politica em construção"; seguindo para as considerações finais.

\section{POLITICA PÚBLICA SOCIAL: UM ELEMENTO CONTRADITÓRIO.}

Colocar em debate o universo da educação e suas imbricadas correlações com as forças sociais, políticas, ideológicas e culturais em nossa sociedade, de fato, não nos parece tarefa simplória. 0 ponto de partida para tal discussão não prescinde da necessidade analisar sobre como, na realidade brasileira, educação e assistência estudantil tem travado suas relações na conformação capitalista dos modos de produção e reprodução da via material e espiritual das sociedades.

Como esclarece Mészáros $(2008$, p. 43) "as determinações gerais do capital afetam profundamente cada âmbito particular com alguma influência na educação, e de forma nenhuma apenas as instituições formais". Ora, é, portanto, atento a isto, que empreendemos a análise das políticas sociais enquanto espaço contraditório.

As mudanças político-econômicas internacionais e as transformações por elas desencadeadas influenciaram, em grande parte o tônus da política social brasileira. (PEREIRA, 2008). As singularidades da política social ao nosso modo se devem à dependência econômica e política da sociedade brasileira no cenário político internacional e no mercado globalizado, e as condições histórico-políticas que condicionam o processo de "regulação social tardia" (SPOSATI, 2002) em um país que somente no final do século XX passou a reconhecer os direitos sociais em um contexto neoliberal.

Como afirma Pereira (2008, p. 125) 
RÊGO, E. C.; BENEVIDES, M. G.

(...) a proteção social no Brasil não se apoiou firmemente nas pilastras do pleno emprego, dos serviços sociais universais, nem armou até hoje, uma rede de proteção impeditiva da queda e da reprodução de estratos sociais majoritários da população na pobreza extrema.

Desde a década de 1990, o Estado brasileiro vivencia sua reconfiguração visando adequar-se à lógica de mercado. (PEREIRA, 2008). A redução de investimentos públicos nas áreas de desenvolvimento social, 0 aumento da focalização e fragmentação das políticas, substancialmente tem garantido indivíduos cada vez mais marginalizados, gerando o empobrecimento material e imaterial das lutas populares.

Como ilustra Santos (2008, p. 03)

O maior êxito neoliberal parece ter se dado no campo da ideologia, tanto que este conseguiu ser implementado de forma hegemônica. De acordo com Borón o discurso ideológico deste projeto político baseia-se na 'supremacia do privado' e na 'satanização do público'. Qualidade seria sinônimo de privado, enquanto que ineficiência e corrupção seriam intrínsecas ao que é público. É a partir desta ideologia que se vem diminuindo a capacidade do Estado de formular e executar políticas públicas.

O acesso aos serviços básicos de qualidade - saúde, educação, habitação acabam atrelados à iniciativa privada, estando disponíveis aos cidadãos-consumidores que podem dispor de tais serviços no mercado. 0 usufruto dos serviços públicos é feito quase que por obrigatoriedade, como a única alternativa - pelos indivíduos impossibilitados de pagar por serviços de melhor qualidade (SPOSATI, 2002).

Segundo Santos (2008, p. 03) "cada vez mais a ideia do cidadão é a de que somente aqueles que podem pagar têm acesso a serviços de qualidade, pois o setor público, ideologicamente, é cada vez mais associado à precariedade".

0 neoliberalismo permite, de forma crescente, a entrada de organismos privados na prestação de serviços públicos essenciais; negocia a entrega dos bens públicos ao grande capital através das privatizações e formula políticas sociais cada vez mais focalizadas e fragmentadas, transformando-as em "[...] ações pontuais e compensatórias direcionadas para os efeitos mais perversos da crise [...]" contrariando o caráter universalizante das políticas públicas (PEREIRA, 2008, p. 156).

Pelo direcionamento neoliberal aos países de economias periféricas, o Estado passa à formulação de políticas sociais privatizadas - com a participação de organismos privados na oferta, segregando os que podem e os que não podem pagar - focalizadas focadas nas ações emergenciais voltadas para os pobres dentre os mais pobres - e descentralizadas - transferindo responsabilidades para outras esferas do poder público, ou para instituições privadas. (PEREIRA, 2008). É, pois; neste cenário que se desenvolvem as políticas de educação e de assistência estudantil.

\section{AS POLÍTICAS PÚBLICAS PARA A EDUCAÇÃO SUPERIOR NO BRASIL}


A partir da compreensão de que os direitos sociais resultam do reconhecimento do poder público às demandas postas pela sociedade civil em um ininterrupto processo de contradição, se constroem as políticas públicas sociais como respostas às necessidades postas pela classe trabalhadora, movimentos sociais etc.

Quando o Estado passa a formular respostas às demandas da classe trabalhadora que, vendo sua condição de vida tensionada pelo agravamento da questão social, exige do Estado intervenções em forma de serviços públicos sociais, são forjadas aí o escopo para a formulação de políticas públicas.

Até a Constituição de 1988 a educação brasileira já tinha percorrido um longo período de muitas reviravoltas entre as ideias pedagógicas e a adoção de sistemas de ensino desde a atuação jesuítica, passando pelo pombalismo, até a pedagogia conservadora e o escolanovismo (SAVIANNI, 2007).

Após o reconhecimento da educação enquanto direito social, demandando a intervenção do Estado em sua efetivação, regulamentado pela Constituição Federal de 1988 , se seguiu uma gama diversificada de documentos que regulamentam, organizam e sistematizam a oferta da educação em todo o território brasileiro.

Precedida da Constituição Federal de 1988, a Lei no 9.694 - Lei de Diretrizes e Bases da Educação - LDB, é uma das mais importantes legislações para o processo de regulamentação da educação enquanto direito social, através da organização, sistematização e operacionalização de políticas sociais de educação.

Certamente, não podemos de neste breve debate pontuar, como a ofensiva neoliberal tem atingido profundamente o terreno dos direitos sociais e das políticas públicas sociais, reduzindo a atuação do Estado, declarando o mercado como único regulador das relações em sociedade, e aprofundando o fosso das desigualdades sociais gerado pela política econômica polarizada e subalternizante.

Sendo assim, nossas análises teóricas neste segundo tomo, da pesquisa concentram-se no debate sobre 0 atual cenário de desmonte às políticas públicas sociais, em especial à educação superior, promovido pela lógica neoliberal e desenvolvimentista (MOTA, AMARAL, PERUZZO, 2012, p.03).

(...) as discussões sobre o desenvolvimento econômico e social são orientadas pelas reformas estruturais na economia, especialmente pela política de privatização dos serviços públicos, reforma do Estado, e focalização de programas sociais para os segmentos mais vulneráveis da sociedade.

Representativos da contrarreforma neoliberal operada no cenário mundial, em que o campo dos direitos sociais sofre sérios rebatimento e profundos ataques, são as políticas atuais de educação, principalmente relacionadas à educação superior.

Nos países latino-americanos, a partir do último quartel do século $X X$, ocorre a redução do espaço do Estado como regulador das relações em sociedade, e a ocupação deste espaço pelo mercado gera um cenário onde tudo se torna mercadoria. 0 redimensionamento do papel do mercado na regulação social modifica a compreensão das políticas públicas e dos direitos sociais (SPOSATI, 2002). 
RÊGO, E. C.; BENEVIDES, M. G.

Em uma sociedade onde tudo é mercadoria, educação também é produto. Assim observamos o crescimento acelerado das instituições privadas de educação especialmente as de nível superior - a formulação de políticas de incentivo ao financiamento de cursos superiores em instituições particulares, como o Fundo de Financiamento ao Estudante do Ensino Superior - FIES, instituído pela Lei o 10.260 de 12 de julho de 2001, criação de programas de fomento à matrículas em faculdades privadas, por meio da concessão de bolsas de estudo - como o Programa Universidade para Todos - PROUNI, instituído pela Lei no 11.096, de 13 de janeiro de 2005.

Vale ainda destacar, o Programa de Apoio a Planos de Reestruturação e Expansão das Universidades Federais (REUNI), instituído pelo governo federal por meio do Decreto no 6096/2007, e que traz uma proposta controversa e duvidosa sobre a real reestruturação que opera nas universidades públicas federais.

[...] uma das mais importantes estratégias adotadas pelo governo para a educação superior, consubstanciada no programa analisado, efetiva-se sob a égide da mesma lógica gerencialista adotada pelos governos neoliberais, ou seja, por meio da maximização de recursos com baixo investimento (MACHADO, 2014, p. 13).

Enquanto direito social, operacionalizado através de políticas públicas sociais, a educação sofre os rebatimentos da ofensiva neoliberal aos quadros de direitos já reconhecidos, visto que este é espaço de correlação de forças onde Estado-SociedadeMercado forjam uma complexa relação de dependência (SPOSATI, 2002).

Ao mesmo tempo que fomenta a iniciativa privada e abre possibilidades para 0 mercado comercializar educação como um produto disponível ao cidadão consumidor, o Estado brasileiro - a partir dos anos 1990 tendo continuidade especialmente nas duas décadas que se seguiram - também possibilita através de políticas afirmativas e da promoção de condições de permanência na universidade; a democratização da educação superior e seu acesso pelos substratos sociais mantidos historicamente à margem dos processos de elaboração dos saberes.

[...] a reforma universitária em curso no Brasil não é um fato isolado, mas está inserida num amplo e complexo processo de transformação da universidade no mundo, condicionado pelas metamorfoses da atual etapa do capitalismo. Mandel (1979) já antecipava que o questionamento do modelo de universidade tradicional e humanista não está ocorrendo em razão do excesso de estudantes, alto custo da formação, falta de infraestrutura material, mas sim por razões econômicas, que demandam a adequação dos currículos, da estrutura e das opções dos estudantes à vertiginosa velocidade das inovações tecnológicas, que caracterizam o capitalismo tardio (PACHECO, 2014, p. 044).

A partir do último quartel do século XX nos países de economia periférica, as políticas públicas sociais são reflexo de desmantelamento e desqualificação da coisa pública. Ao passo que contraditória tem sido a política de educação, que diz democratizar acesso, mas opta por aligeirar a formação, privatizar o ensino superior, demonstrando quase nenhum zelo à qualidade da formação sempre mais profissionalizante e concatenada às exigências do mercado; contraditória também tem 
sido a política de assistência estudantil, que insistimos em assim denominá-la, por força de nossa compreensão que esta não deve ser menos que política pública social.

\section{ASSISTÊNCIA ESTUDANTIL: UMA POLITIICA EM CONSTRUÇÃO}

A política de assistência estudantil tem em sua gênese práticas que ensaiavam algum tipo de amparo aos alunos dos cursos superiores já desde 1928, quando o Brasil não dispunha de universidades em seu território, e a saída encontrada pelos filhos das elites para os estudos era se deslocar a outros países, como Portugal e França (ARAÚjo, 2007 apud SILVEIRA, 2012). Fundações de casas de estudantes, restaurantes para alunos, ações que vieram ao longo dos anos se desenvolvendo pontualmente e de forma desarticulada, sem a concepção de direito social a lhes embasar.

Com governo de Getúlio Vargas algumas indicações de ações mais estruturadas são propostas. A reforma do sistema de educação do país, em 1931, denominada Reforma Moreira Campos - Decreto no 19.85/1931 - que dispõe sobre o ensino superior no Brasil, a criação do Conselho Nacional de Educação - Decreto no 19850/1931 - e o Estatuto da Organização das Universidades Brasileiras - Decreto № 19.851/1931, dão corpo a estruturação de um conjunto jurídico-legal que vai dando forma ao sistema de ensino no país (SILVEIRA, 2012).

A partir daí a assistência estudantil iniciou seu processo de construção e desenvolvimento contando nas Constituições de 1934, 1937 e 1946 com artigos que ora Ihe tratavam como "ajuda aos necessitados", ora como "assistência educacional", mas sem, contudo, status de direito social dos alunos (SILVEIRA, 2012, p. 56).

Conforme Silveira, em 1946, a educação passa a ser considerada direito de todos, e a assistência estudantil prevista, obrigatoriamente, em todos os sistemas de ensino, para os "necessitados" (2012, p. 53). A Constituição de 1967 aborda a educação como direito de todos e prevê a igualdade de oportunidades.

Art. 168 - A educação é direito de todos e será dada no lar e na escola; assegurada a igualdade de oportunidade, deve inspirar-se no princípio da unidade nacional e nos ideais de liberdade e de solidariedade humana;

$\S 2$ ㅇ - Cada sistema de ensino terá, obrigatoriamente, serviços de assistência educacional que assegurem aos alunos necessitados condições de eficiência escolar (SILVEIRA, 2012, p. 56).

A Constituição 1988 é o principal marco legal da educação enquanto direito a partir da compreensão contemporânea dos direitos sociais. E a partir daí a assistência estudantil de fato é abordada no texto legislativo com a Lei de Diretrizes e Bases - Lei no 9.394/1996, onde em seu Art. $3^{\circ}$, regulamenta que "o ensino será ministrado com base nos seguintes princípios: I - igualdade de condições para o acesso e permanência na escola (...)" (BRASIL, 1996).

A igualdade de oportunidade constitui um princípio que, segundo seus pressupostos ideológicos, tem como objetivo possibilitar a determinados segmen- 
RÊGO, E. C.; BENEVIDES, M. G.

\begin{abstract}
tos que se encontram em situação de vulnerabilidade sociocultural, condições equivalentes àquelas que, supostamente, já transitam como sujeitos de direitos. Em tese, por esse princípio, os indivíduos devem partir de uma posição social igual para que consigam atingir seus objetivos pessoais, profissionais, enfim, para que possam, como iguais, se mover no cotidiano (SILVEIRA, 2017 apud SANTOS, 2010, p. 186).
\end{abstract}

E assim o Programa Nacional de Assistência Estudantil - PNAES, instituído pelo Decreto no 7.234/2010, compreende a necessidade de ações que possam garantir condições de igualdade no acesso e permanência dos alunos nas Instituiç̧ões de Ensino Superior - IES. O programa, portanto, vêm corroborar a noção de direito social da assistência estudantil, muito embora venha recortado por critérios de elegibilidade que tornam a política seletiva e focalizada.

A Assistência Estudantil realiza atividades que possibilitem a permanência do aluno na universidade, contribuindo para que este goze das condições necessárias de vida, viabilizando sua participação nas diversas experiências acadêmicas. Preconizados no Art. $2^{\circ}$ do PNAES, os objetivos da Assistência estudantil são (BRASIL, 2010, p. 01):

I - democratizar as condições de permanência dos jovens na educação superior pública federal;

II - minimizar os efeitos das desigualdades sociais e regionais na permanência e conclusão da educação superior;

III - reduzir as taxas de retenção e evasão; e

IV - contribuir para a promoção da inclusão social pela educação.

Muito embora os avanços na política de Assistência Estudantil com a expansão e composição das equipes multiprofissionais, estruturação de serviços, o alcance do status de decreto - ainda que isto também possa denotar a fragilidade da política que há quatro anos espera tornar-se lei - desafiador é o trabalho que se tem pela frente na construção de uma política pública de assistência estudantil, seja no campo jurídicolegal, seja no terreno neoliberal adverso às políticas sociais (SPOSATI, 2002).

Certamente a política de assistência estudantil vinculada ao direito à educação representa um ganho inquestionável no âmbito das políticas de educação superior no país uma vez que se propõe democratizar o acesso à educação incorporando demandas dos movimentos estudantis como o direito a alimentação, moradia e políticas de incentivo e de permanência nas IES. Contudo, não se pode furtar essa assertiva de considerar como o cenário neoliberal impacta na formulação das respostas estatais no âmbito da assistência estudantil.

A partir do PNAES, a democratização nas condições de permanência, a minimização das desigualdades sociais e regionais, a redução na evasão e na retenção além da promoção da inclusão social estão vinculadas a uma compreensão de equidade do acesso às políticas públicas (BRASIL, 2010).

Os objetivos da assistência estudantil vêm atrelados à adoção crescente pelas universidades públicas do Exame Nacional do Ensino Médio - ENEM instituído pela Portaria no 438, de 28 de maio de 1998; e do Sistema de Seleção Unificado - SISU instituído pela Portaria Normativa MEC $n=2$, de 26 de janeiro de 2010, que facilitam o in- 
tercâmbio entre estudantes e IES em todo o território nacional, aumentando o número de deslocamentos de alunos; e às políticas afirmativas de cotas sociais que possibilitaram 0 ingresso de estudantes provenientes das camadas sociais historicamente posicionadas à margem do acesso ao ensino superior no país, demandando programas e serviços de assistência estudantil a fim de garantir a permanência destes públicos nas universidades (MACHADO, 2017).

\begin{abstract}
A adesão ao sistema pode gerar uma série de alterações no perfil dos estudantes que ingressam na universidade, uma vez que o candidato pode escolher até duas das instituições participantes em todo o território nacional e eleger até dois cursos para concorrer a uma vaga. Essa possibilidade pode aumentar o número de migrações para cursar a graduação, o que tende a gerar novas demandas no campo da assistência estudantil (MACHADO, 2017, p. 245).
\end{abstract}

As políticas sociais de democratização do ensino superior, portanto, devem aliar ações que contemplem a esfera do acesso, mas em igual medida necessitam abarcar ações consolidadas e abrangentes de permanência no ensino superior. Logo, entendese, que a democratização da educação superior congrega políticas sociais que sintetizem ações no âmbito do acesso, mas essencialmente, estejam relacionadas às políticas de permanência nesta modalidade de ensino (SILVEIRA, 2012).

Visando democratizar a permanência na educação superior, minimizando as desigualdades sociais, combatendo os índices de evasão e retenção e promovendo a inclusão social por meio da educação, a política de assistência estudantil tem contribuído para que grupos, historicamente excluídos dos espaços de produção do conhecimento, possam permanecer nas instituições de ensino superior, alcançando os níveis mais elevados do ensino, da pesquisa e da produção artística (MACHADO, 2017).

As ações da assistência estudantil visam promover a igualdade de condições de permanência nas IES aos alunos com insuficiência de condições financeiras, agindo preventivamente nas situações de retenção e evasão e criando condições de melhoria do desempenho acadêmico (BRASIL, 2010).

De acordo com o Programa Nacional de Assistência Estudantil - PNAES, instituído pelo Decreto no 7.234/2010, as ações da assistência estudantil deverão ser desenvolvidas nas áreas da alimentação, moradia, transporte, saúde, cultura, inclusão digital, creche, esporte, apoio pedagógico e acesso, participação e aprendizagem de estudantes com deficiência, transtornos globais do desenvolvimento e altas habilidades e superdotação, tendo, prioritariamente, como alvo o público discente proveniente do ensino público ou com renda per capita de até um salário mínimo e meio, matriculado em cursos de graduação presencial nas IES.

Políticas sociais no cenário neoliberal são caracterizadas pela elaboração de programas e ações baseadas na renda ou em sua ausência, e na monetarização das demandas sociais - tratadas como individuais - por meio da transferência de renda direta aos "beneficiários" que seguem um rígido protocolo de fiscalização, avaliação e adequação às condicionalidades e deveres necessários para que estes se mantenham na qualidade de "atendidos" (SPOSATI, 2002). 
RÊGO, E. C.; BENEVIDES, M. G.

\begin{abstract}
A assistência estudantil se efetiva, em grande parte, com ações de transferência de renda. Ou seja, recursos diretamente depositados nas contas dos estudantes que recorrem aos serviços privados para garantirem o suprimento de suas necessidades básicas, contribuindo para o processo de monetarização em substituição à construção de equipamentos e serviços públicos (MACHADO, 2017, p. 250).
\end{abstract}

Os "beneficiários", neste contexto, não alcançam um lugar de cidadãos com direitos reconhecidos, mas apenas usuários temporários que devem cumprir exigências a fim Ihes garantir - como passes - sua permanência na condição de população atendida (SPOSATI, 2002).

Tal panorama desvincula a concepção de direito social da política social uma vez que esta "é operacionalizada de forma seletiva, focalizada e condicionada. Uma lógica cada vez mais comum nas políticas sociais, mas que aparecem enquanto retrocesso, contrariando aspectos universalizantes e de promoção de justiça social" (MACHADO, 2017, p. 250).

Mesmo que a política de assistência estudantil venha atender uma demanda crescente de permanência no ensino superior redimensionada pela expansão das IES, aumento no número de vagas e políticas afirmativas de cotas é preciso considerar que o delineio das ações, em grande parte, não tem coadunado com o compromisso de democratizar, universalizar e incluir socialmente pela educação, uma vez que desvincula a compreensão do direito, não investe na qualidade dos serviços articulados com o conjunto maior das políticas públicas, e individualiza as demandas estudantis por moradia, alimentação, transporte concentrando os investimentos na transferência direta por meio de auxílios estudantis.

Grande parte dos programas sociais estatais sob a tal orientação são substituídos por programas de transferência de auxílios regulares mensais sob a forma de renda mínima. Este submete a possível garantia social ao "desejo" do beneficiário em consumir os bens postos ao alcance do auxílio recebido. Neste caso, se alia uma política de mercado a uma condição de provisão social. (SPOSATI, 2002, p. 27).

Tal recorte é desenhado no contexto de impacto do neoliberalismo nas políticas sociais. As margens que delineiam tal concepção destacam-se na assistência estudantil como herança das políticas de reestruturação as universidades públicas, implantação de sistemas de avaliação do ensino superior, amplo financiamento público em instituições privadas e a consolidação da lógica produtivista e mercadológica na produção do conhecimento (MACHADO, 2017).

A política de assistência estudantil, tal como temos hoje, um programa de abrangência nacional e estabelecido por meio de normativas do governo federal, tem sua gênese articulada ao Programa de Apoio a Planos de Reestruturação e Expansão das Universidades Federais (Reuni), um dos principais programas da contrarreforma universitária iniciada no período neoliberal (MACHADO, 2017, p. 240).

A política de assistência estudantil tem sido adjetivada pela focalização, ainda que este traço possa aparentar minimizado pelo caráter prioritário, e não completamen- 
te excludente aos demais grupos. A destinação orçamentária e o contingenciamento dos recursos públicos limitam o acesso a estas políticas, cada vez mais, para os mais pobres; e assumem o papel de eliminar os que pelo critério de renda ou de acesso ao ensino privado não "necessitam" da assistência estudantil.

\section{CONSIDERAÇÕES FINAIS}

Diversos motivos interferem no abandono do curso superior. Inúmeros estudos se dedicam a esta questão. A vulnerabilidade social é certamente um elemento agravante importante para a permanência ou 0 abandono dos cursos nas IES. A desistência da formação em nível superior, ao nosso ver, pode estar atrelada a inúmeros elementos que, associados ou não, interferem na permanência dos alunos nos cursos. Situações de violência, desigualdades, discriminações, assédios e autoritarismos podem atuar fortemente no processo de evasão escolar.

Em síntese, as reflexões por ora ensejadas, apontam que a) a política social de assistência estudantil na atualidade tem se caracterizado pela focalização do seu alcance, o que interfere no seu objetivo de democratização da permanência no ensino superior; b) tem fortemente atrelado a permanência dos alunos nas IES aos critérios de renda per capita; perspectiva que não alcança a profundidade do processo excludente e de desigualdade que se dá em complexidade; c) tem investido na monetarização das necessidades, transferindo individualmente aos usuários a responsabilidade por superar os riscos sociais, por meio do recebimento de suporte pecuniário, sem priorizar investimentos em equipamentos e serviços de qualidade como restaurantes universitários, moradias estudantis, transporte estudantil etc.

Evidentemente que a contribuição da política de assistência estudantil à democratização do direito humano à educação, e especificamente ao acesso ao ensino superior, para tornar-se efetiva, necessita associar-se ao conjunto de demais políticas públicas que estejam ancoradas em um contrato social de amplo alcance e de grande profundidade no reconhecimento da cidadania e dos direitos humanos.

Os desafios são, por vezes, desalentadores. Reconhecer-se como política social em um cenário neoliberal, é confessar os limites das respostas estatais do Estado mínimo. Contudo, é também provocar estratégias de resistências ao processo de inculcação da cidadania pelo mercado e de focalização nos "necessitados", é opor-se à lógica policialesca e fiscalizatória contra as fraudes na comprovação das condições de vulnerabilidade social; é não ceder ao esvaziamento político nas atividades realizadas.

Nesta linha, este estudo reafirma a necessidade de fortalecimento das atividades pedagógicas junto à comunidade discente que atuem no sentido de qualificar o debate acerca da fragilização da política de assistência estudantil, ampliando os espaços de participação da comunidade discente nos espaços deliberativos e de execução da política de assistência estudantil.

É essencial ainda que haja tensionamento quanto à destinação orçamentária para esta pasta, uma vez que a fixação de percentuais e a garantia de investimentos são 
RÊGO, E. C.; BENEVIDES, M. G

medidas urgentes para a consolidação da assistência estudantil como política de democratização do acesso a educação superior.

Artigo recebido em: 30/10/2018

Aprovado para publicação em: 21/12/2018

\section{STUDENT ASSISTANCE AND A REDUCTION OF SOCIAL INEQUALITIES IN THE CONTEXT OF SOCIAL POLICY FRAGILIZATION}

ABSTRACT: This article reflects on the policy of student assistance in the neoliberal context of the weakening of social policies. We propose the reflexive exercise on the contradictions of social policy that intends to democratize the permanence to higher education, but is equated by the neoliberal model of minimum state. The methodology used the documentary research to the main national legislations, besides the bibliographical research. Student assistance is potentially strategic for the democratization of access and permanence in public higher education, but the contingencies operated by the neoliberal logic on social policies in peripheral economy countries outline actions that do not conform to the commitment to socially include education, operating the formulation of focused and fragmented programs that present difficulties in guaranteeing the right.

KEYWORDS: Social Policy. Student Assistance. Neoliberalism. Education..

\section{LA ASISTENCIA ESTUDIANTIL Y LA REDUCCIÓN DE LAS DESIGUALDADES SOCIALES EN EL CONTEXTO DE FRAGILIZACIÓN DE LAS POLITICAS SOCIALES}

RESUMEN: Este artículo refleja sobre la política de asistencia estudiantil en el contexto neoliberal de fragilización de las políticas sociales. Proponemos el ejercicio reflexivo sobre las contradicciones de la política social que pretende democratizar la permanencia a la enseñanza superior, pero es ecuacionada por el modelo neoliberal de Estado mínimo. La metodología empleó la investigación documental a las principales legislaciones nacionales, además de la investigación bibliográfica. La asistencia estudiantil se configura potencialmente estratégica para la democratización del acceso y la permanencia en la enseñanza superior pública, sin embargo los contingentes operados por la lógica neoliberal a las políticas sociales en los países de economía periférica delinean acciones que no concaten con el compromiso de incluir socialmente por la educación, operando la formulación de programas focalizados y fragmentados que presentan dificultades en la garantía del derecho.

PALABRAS CLAVE: Política Social. Asistencia Estudiantil. El neoliberalismo. Educación.

\section{REFERÊNCIAS}

BRASIL. Dispõe sobre o Programa Nacional de Assistência Estudantil - PNAES. Casa Civil Subchefia para Assuntos J urídicos. Decreto 7.234 de 19 de julho de 2010. Brasília. 
Disponível em: http://www.planalto.gov.br/ccivil 03/_ato20072010/2010/decreto/d7234.htm. Acesso em: 10 fev. 2015.

. Lei de Diretrizes e Bases. Ministério da Educação, Decreto no 9.394 de 20 de dezembro de 1996. Brasília, DF, 1996. Disponível em: http://portal.mec.gov.br/seesp/arquivos/pdf/lei9394_Idbn1.pdf.Acesso em: 12 jun. 2010.

MACHADO, F. M. Financiamento da assistência estudantil nas universidades federais. Temporalis, Brasília, ano 17, n. 33, jan./jun. 2017.

MÉSZÁROS, I. Para Além do Capital. Rio: Boitempo, 2008. Disponível em: $\leq h$ ttps://nupese.fe.ufg.br/up/208/o/para-alem-do-capital.pdf?1350933922>. Acesso em: 08 mai. 2012.

MOTA, A. E.; AMARAL, A.; PERUZZO, J . O novo desenvolvimentismo e as políticas sociais na América latina. In: MOTA, A. E. (org.) Desenvo/vimentismo e Construção de Hegemonia. São Paulo: Cortez. 2012.

PACHECO, J. A. Impactos do REUNI nas instituições federais de ensino superior: expansão ou subordinação. In: XIV Colóquio Internacional de Gestão Universitária, 2014. Florianópolis, Disponível em:<https://repositorio.ufsc.br/bitstream/handle/123456789/131879/2014230.pdf?sequence=1>Acesso em: 10 jan.2019.

PEREIRA, P. A. Necessidades humanas. subsídios à critica dos mínimos sociais. São Paulo: Cortez, 2008.

SANTOS, V. M. Políticas Públicas em Educação: a "lógica subalternizante" vigente na América Latina e seus reflexos na universidade brasileira. Revista Emancipação, n. 8.1, set. 2008. semestral.

SAVIANI, D. História das Idéias Pedagógicas no Brasil. Campinas: Autores Associados, 2007. $472 \mathrm{p}$

SILVEIRA, M. M. A Assistência Estudantil no Ensino Superior: uma análise sobre as políticas de permanência das universidades federais brasileiras. Pelotas: 2012. $134 \mathrm{f}$. Dissertação (Mestrado em Política Social) - Centro de Ciências Jurídicas, Econômicas e Sociais, Universidade Católica de Pelotas. Pelotas.

SPOSATI, A. Regulação social tardia: características das políticas sociais latinoamericana na passagem entre o segundo e terceiro milênio. 2002. Disponível 
RÊGO, E. C.; BENEVIDES, M. G.

em: $\leq h t t p: / / w w w 1 . l o n d r i n a . p r . g o v . b r / d a d o s / i m a g e s /$ stories/Storage/sec_assistencia/pdf Regulacao_social_tardia_Aldaisa.pdf $>$ Acesso em: 08 mai. 2012.

ERnny Cô̂lho RêGo: É Mestre em Planejamento e Políticas Públicas do Programa de Pós-Graduação em Planejamento e Políticas Públicas da Universidade Estadual do Ceará. É especialista em Serviço Social, Políticas Públicas e Direitos Sociais pela Universidade Estadual do Ceará (2012). Possui graduação em Serviço Social pela Universidade Estadual do Ceará (2010). É Assistente Social do Instituto Federal de Educação, Ciência e Tecnologia do Ceará - IFCE. Atualmente coordena a Coordenação de Assistência Estudantil no IFCE - Campus Jaguaribe. Tem experiências e pesquisas nas áreas de Políticas Públicas, Direitos Humanos e Educação em Direitos Humanos.

E-mail: dedacrego@hotmail.com

Marinina Gruska Benevides: Pós-Doutora em Democracia e Direitos Humanos (IGC/Universidade de Coimbra-Portugal), Pós-doutoranda em Antropologia e Sociologia (PUC-SP), Doutora em Sociologia (UFC), Mestra em Sociologia (UFC), Especialista em Recursos Humanos (USP), Especialista em Psicologia Organizacional e do Trabalho $(C R P)$, Especialista em Abordagem Sistêmica da Família (UNIFOR) e Especialista em Medicina Tradicional Chinesa (UECE), Bacharel em Psicologia (UNIFOR), Bacharel em Direito (UNIFOR). Professora Associada da Universidade Estadual do Ceará, atuando no Doutorado em Políticas Públicas, no Mestrado Profissional em Planejamento e Políticas Públicas e no Curso de Ciências Sociais. Tem experiências e pesquisas nas áreas de Políticas Públicas, Direitos Humanos e Ambiental, Psicologia das Organizações e do Trabalho, Sociologia do Trabalho e das Empesas, Psicologia Social, Sociologia da Família. E-mail: marininagruska@gmail.com

Este periódico utiliza a licença Creative Commons Attribution 3.0, para periódicos de acesso aberto (Open Archives Iniciative - OAI). 